\title{
The 1866 Vercoe and Harding map and the axonometric: the object of subjective representation
}

\section{Katherine O'Shaunghnessy}

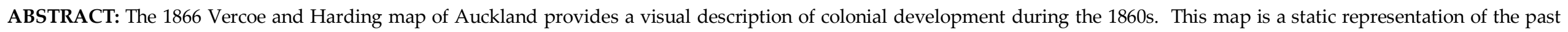

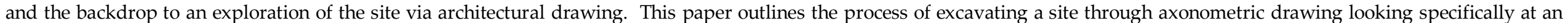

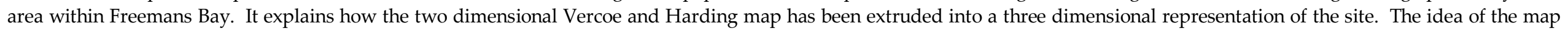

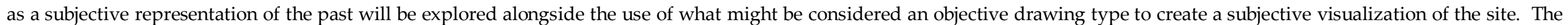

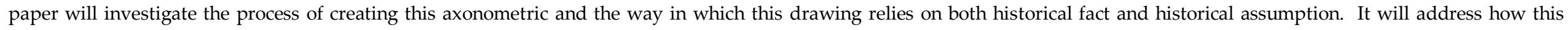

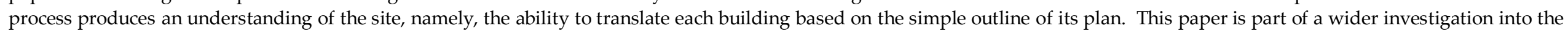

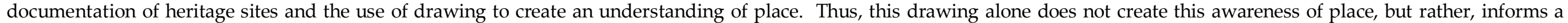
new understanding of the 1866 map and a representation of what Freemans Bay might have been during the 1860s.

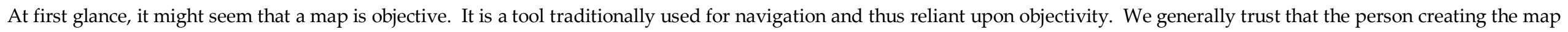

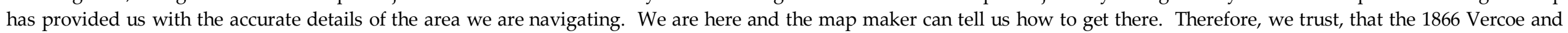

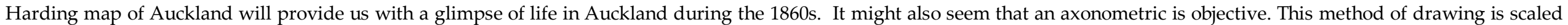

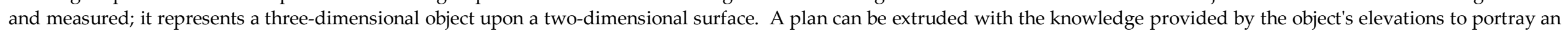

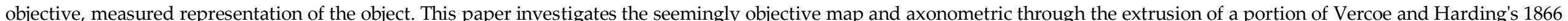

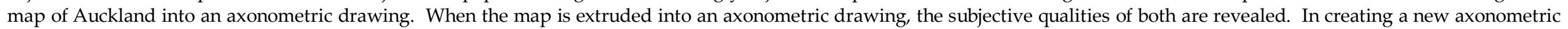

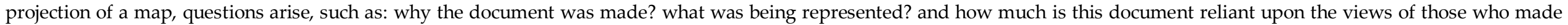

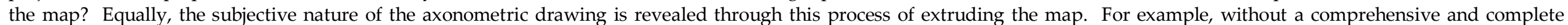

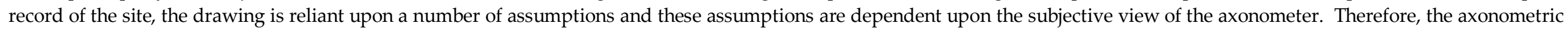

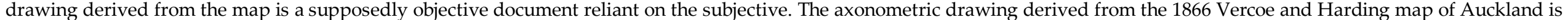

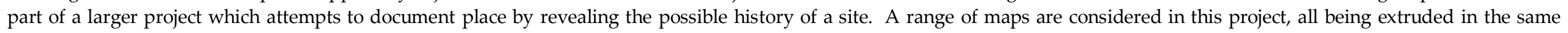

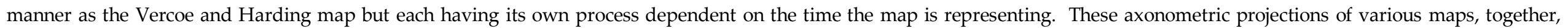
aim to represent both time and space and to convey a sense of place.

\section{The 1866 Vercoe and Harding map of Auckland}

Maps are an essential tool for developing a nation, from its initial discovery right through to the creation of its modern economic and social infrastructure. Maps record what is known about a place, and at different points in time. Maps are a unique portrayal of place, displaying a wide range of phenomena in a way that is virtually impossible via any other medium. ${ }^{1}$

At the time it was made, the 1866 Vercoe and Harding map of Auckland might have been viewed as an essential tool for developing

${ }^{1}$ Marshall From sextants to satellites: A cartographic time line for New Zealand p iii.
New Zealand. It could be assumed that this map provided a method of valuing the land and gave settlers an idea of where potential expansion was needed and to enable the local government to establish control over the city. Furthermore this map would have been an assertion of European dominance and a tool to legitimize their settlement. The surveyors 
would have been aiming to portray a true representation of Auckland in 1866 by producing this map. However, this plan format of buildings, roads and coastline produces a flatscape of European settlement. This paper interprets the map as a subjective representation of Auckland in 1866. That is to say, the subjective view of the map maker. This map is nonetheless an important tool in understanding Auckland and in particular Freemans Bay during the 1860s.

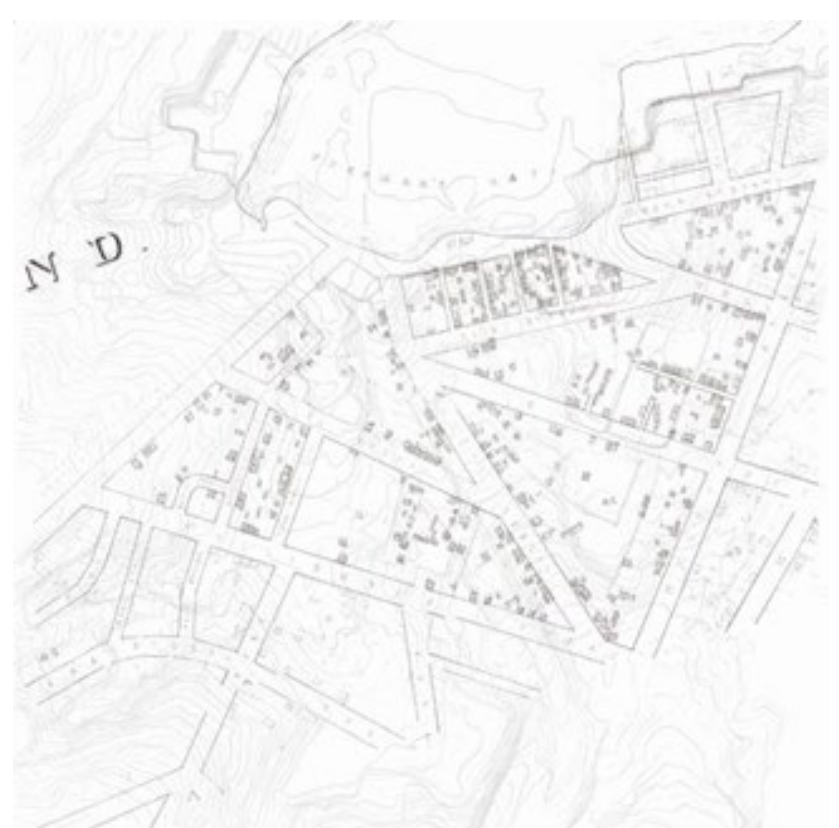

Figure 1: City of Auckland, New Zealand, September 1866. Axonometric by K O'Shaughnessy, 2010.
This paper critically addresses the Vercoe and Harding map of Auckland in a way that will potentially open up the time and place of that this document is representing. This map is an object in itself; it presents and excludes information within a set format whilst also being very much a subjective representation from J Vercoe and LW Harding. This project will address the map as an object upon which to draw information from and onto. Also, to address this map as an object is to consider the subjective views from which the map was generated.

mapping in design and planning has been undertaken conventionally as a quantitive and analytical survey of existing conditions made prior to making a new project.

There is generally an intended objectivity in map making. The title of the map in question addresses this intention well. At the top left hand corner is written, "City of Auckland, New Zealand, From actual survey of J Vercoe and LW Harding. September 1866." The word actual in this instance highlights the intended objectivity as if to say, this was measured and therefore is fact. In reality, this map is dependent upon the process and views of $\mathrm{J}$ Vercoe and LW Harding.

The meaning of the word map might suggest a measured and therefore objective document of a place. However, it has been argued that this so-called objective document should be considered a tracing rather than a map of the site involving a process which goes beyond the objective measured components of a site:

The map does not reproduce an unconscious closed in upon itself; it constructs the unconscious ... The map has to do with performance, whereas the tracing always involves an "illeged competence."2

The Vercoe and Harding map of Auckland is a framed document, bordered by the extent of settlement at the time the survey was taken. It might be assumed that there would not have been any serious boundaries at this time of potential colonial expansion. This is evident in that where the map has been framed the roads seem to dissipate as if to acknowledge a continuation of growth and development. As this map describes, the extents of Auckland were east to west from Mechanics Bay to Franklin Road and north to south, from the harbour to Ponsonby Road. This paper considers part of the Freemans Bay area, selected due to the dynamic qualities of both permanence and change of this part of Auckland. It uses Freemans Bay as an

${ }^{2}$ Corner "The Agency of Mapping" p 214. 
example as to how the entire map (and other maps) could potentially be assessed.

\section{The axonometric drawing of the Vercoe and Harding map}

Map devices such as, frame, scale, orientation, projection, indexing and naming reveal the artificial geographies that remain unavailable to human eyes. ${ }^{3}$

Part of the purpose of this project is to make such artificial geographies legible in a way which might enhance the reading of this important historical map. This project involves a new projection of the 1866 map; an axonometric drawing which extrudes the plans of this map into a three-dimensional reading of the site.

Each of the suggested forms on the Vercoe and Harding map, that is to say, the rectangles and squares which might suggest a form of dwelling or any sort of building, has been investigated to create an axonometric drawing of each. The drawings are a hybrid of both historical fact and historical assumption. Each potential structure is considered in terms of its use, materiality, orientation, height and relationship to the landscape.

${ }^{3}$ Corner "The Agency of Mapping" p 215.

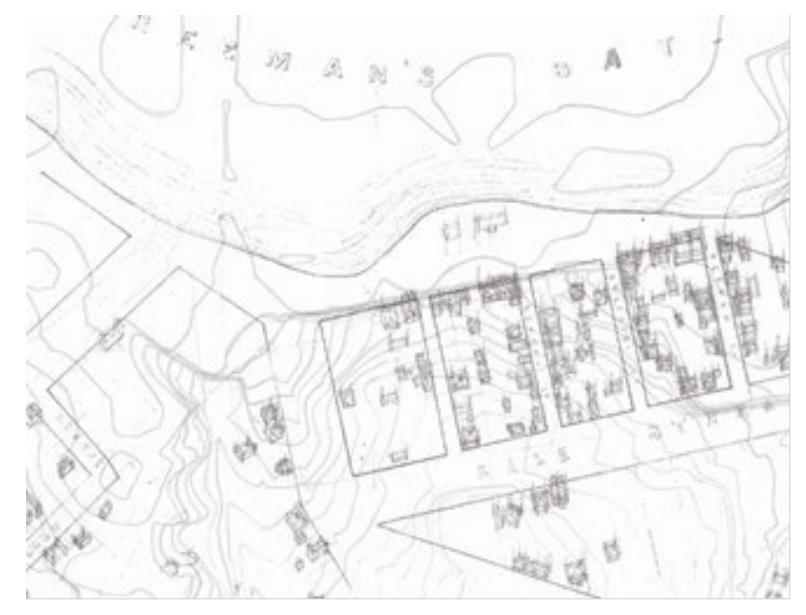

Figure 2: City of Auckland, New Zealand, September 1866. Axonometric by K O'Shaughnessy, 2010.

The rectangular outlines from the Vercoe and Harding map inform the eventual axonometric mapping of the site. Each of these forms has been extruded to create an axonometric drawing of the map. The axonometric has been used in this instance to represent the third dimension and to maintain the presumed measured and objective qualities of the map.

The Vercoe and Harding 1866 map of Auckland is orientated so that north is tilted approximately $45^{\circ}$ clockwise from the top of the page. The grid of the roads is thus presented on this tilt and is aligned from north to south and east to west. This dictated orientation within the plan format adds to the indecipherable, artificial geographies of this map. The use of the axonometric drawing aims to challenge any suggestion of a fixed viewpoint.

The axonometric projection makes each building transparent in a way that all elevations are made visible. Bois states, "There is no negotiation of depth; instead, it is geometrically rendered infinite: the eye is no longer fixed to a specific place and the view is no longer trained or "petrified"."4

axonometry is not so much a means of representation as a tool for work and for objectified work. It can be as perspicuous as you like (and it is not always so, since it's a fact that the public very often can't decipher it). Nonetheless it first of all reveals a poetic standpoint and calls for specialized knowledge. ${ }^{5}$

The axonometric drawing is generally considered an objective drawing tool; that which maintains the scale measure of plan, elevation and section while bringing the drawing into the third dimension. However, axonometric projections not only portray the

${ }^{4}$ Bois "Metamorphosis of Axonometry" p 46.

${ }^{5}$ Reichlin "Reflections: Interrelations between Concept, Representation and Built Architecture" p 67. 
accurate and objective but also, "the view of reality they purport to give us is false; axonometric projections are at once mathematically accurate and untrue in the sense of unreal." 6 Thus, what is provided by these axonometrics is a distorted view produced via a collection of objective information of the site. It is the axonometric's objective knowledge which enhances the subjective reading of the drawing.

Similar to the intended objectivity of the 1866 map, this new projection uses a technique that traditionally displays a geometric truth. However, this does not suggest that the new projection of the 1866 map does not maintain a perceptive ambiguity, "axonometric space is atopical and polymorphous - it is "abstract."'"7 It has been argued that the axonometric's removal from the laws of perception, and because it is so closely based upon the depicted object, that the drawing, "appears too "strange" to be mistaken for the object itself." The ambiguity of the axonometric drawing is further highlighted by the absence of shadows and hence a rejection of the ground in this

\footnotetext{
${ }^{6}$ Nevins and Stern The Architect's Eye p 14.

${ }^{7}$ Bois "Metamorphosis of Axonometry" p 57.

${ }^{8}$ Schneider "Perspective refers to the viewer,
} axonometry refers to the object" $\mathrm{p} 81$. sense. Shadows have indicated certainty in the drawing, "de la Gournerie demands that axonometers use shadows in their drawings, "When a view includes shadows there can be no doubts"."9 As such, it might be said that this ground-less quality of this axonometric drawing might ignore the landscape and thus ignore the place: "The axonometric image is reversible; it tears free of the ground (Malevich's term), facilitating aerial views."10 However, through this process, as will be discussed later in this paper, the landscape informs the construction of the drawing. The drawing might appear as if it hovers above the ground, yet it relies on the ground in its formation.

The axonometric drawing is a presentation of both architectural and psychological excavations and also a hybrid of the two. It is difficult to distinguish between what is architectural: that which exists, or existed and what is psychological - that which is based on the architect's act of blindness. This act of blindness involves the ability to represent that which is not visible. ${ }^{11}$ The

\footnotetext{
${ }_{9}^{9}$ Bois "Metamorphosis of Axonometry" p 56.

${ }^{10}$ Bois "Metamorphosis of Axonometry" p 57. Note: Bois' brackets.

${ }^{11}$ Wood "Drawing the Line" p 56.
}

projections of what Freemans Bay in the 1860s may have been are created by the collection of information gained from existing documentation but also a number of assumptions. Such assumptions are an exercise of the blind architect and a legitimate re-creation of history in these terms.

\section{Process}

The initial process in producing the axonometric involved the use of published material, analyzing photography and studying later maps of the same area. The three-dimensional and scaled nature of the axonometric dictates that without a large amount of existing historic documentation, much of what is projected is assumed.

Historical photographs were key in providing the information needed for the drawing. The photographs used were dated from 1870 through to the present. For example, Henry Winklemann's 1905 photograph which includes Union Street provides a great insight as to what each of the plans along Union Street from the 1866 map might have been in terms of each building's three dimensional form. This photograph shows a series of cottages which face the camera as being timber dwellings with verandahs and across 
the road. It shows similar dwellings with leantos attached to the back of each cottage. In this instance, the front elevation of the houses which face the camera becomes a certainty while the rear elevation becomes assumed as this is based on those cottages facing away from the camera.

As the photographs collected are from various time periods beyond 1866, the use of later maps assists in locating the buildings from the photographs on the 1866 map. The 1908 Wrigg City Plan provides a large amount of information about Auckland City during this period. Each building on this map is described in terms of its height and materiality in a two-dimensional plan form. For example, within the outlined plan of a building is written " $1 \mathrm{~W}$ ', representing a one storey, wooden building. The legend for this map includes elevational views to elaborate upon the description of each building, which in turn highlights the need to consider the topography of the site. For instance, a building might be described as being a single storey as this is what is apparent from the street, yet the building will in fact be two storeys as the land descends beyond street level. In this way, the map acknowledges the limits of presenting the site in two dimensions even when assisted with text and a legend.

In order to locate the buildings present from the 1908 map on the 1866 Vercoe and Harding map, a filtering process takes place. This includes the use of another map produced between these two time periods; the 1882 Hickson map of Auckland. These three maps need to be scaled and overlaid so that each map can relate to the next. When it appears that a building plan translates itself onto another, this plan is highlighted so that a pattern emerges in which buildings from 1866 still existed in 1908. Evidently the information produced from this is very much part of an assumed process for the reason that a building might have been demolished and replaced within this 42 year period. This process adds to the value of the information obtained by photography and provides another potential layer of information to those buildings on the map which are otherwise undocumented.

As previously stated, it is imperative to consider topography when projecting each of these buildings in a three-dimensional manner. Before commencing the initial projections of the 1866 map, a contour map of the present topography was drawn in order to inform the eventual axonometric drawings.
This inclusion of the landform when constructing these drawings influences the overall height and form of the projected building.

Information was also obtained from the use of published material. This complemented the photography and maps to provide ideas of cultural background and materiality. Jeremy Salmond states:

In 1858 of the 12812 houses in New Zealand almost eighty per cent were built of wood, two and a half percent of brick or stone, and the rest of other materials including earth, raupo or canvas. Nearly half had only one or two rooms and a further quarter had three or four rooms. By 1860 the small timber house had become established as the New Zealand vernacular dwelling, and from this little wooden cottage the forms of other ordinary New Zealand houses developed. ${ }^{12}$

Such statistics of materiality are translated onto the drawing by means of building form rather than a detailed drawing of each weatherboard. The materiality of these houses will be further investigated in this project with a change of scale that will inform a more detailed analysis of a single building within this area of Freemans Bay.

${ }^{12}$ Salmond Old New Zealand Houses 1800-1940 p 60. 
Accounts of early Freemans Bay also assist in the construction of the 1866 axonometric drawing:

Te To or Te Too (meaning "the dragging of the waka") was an important fortified pa on the western headland above Freemans Bay...The headland pa was used as a place of refuge in an attack; a village, or papakainga would have been located on flatter land. After the arrival of European settlers, Maori continued to visit Te To, and storehouses were established there during the 1850s to provide food for the surrounding district. ${ }^{13}$

This cultural background, while not directly translated into the form and materiality of each building, provides a layer of knowledge to assist in the assumed projections of the drawing.

The original map has been scaled from its original chains per inch scale to 1:2000. This translates imperial to metric and plan to axonometric. As there are a substantial number of buildings included on this drawing, boundaries have been set up from the harbour to Wellington Street and from Franklin road to Nelson Street. This is not to suggest this boundary restricts anything beyond what has been drawn rather that each

${ }^{13}$ Carlyon and Morrow Urban Village: the story of Ponsonby, Freemans Bay and St. Mary's Bay p 20. building beyond this can be projected in the same manner, setting up an infinite process.

\section{The axonometric representation of place}

Even with a restricted number of buildings, the process becomes repetitive in a way that initiates an intuitive response to each of the plans on this map. What becomes interesting here is a new understanding of the 1866 map and the ability to translate each building based on the simple outline of its plan. For example, it could be assumed that the square format plan on the map would represent a timber cottage with a hipped roof, whereas the rectangular plan might represent a two storeyed cottage with a gable roof.

Frascari believes that drawing is the prediction of architectural events, that of construction and construing. ${ }^{14}$ Several layers of thought exist within these two strategies rather than a single Cartesian project. Through the process of drawing, the designer performs a multi-modal dialogue, "in their analogic procedures they follow the Vitruvian precept that indicates construction as "a continuous and meditative process" (fabrica est continuata ac trita usus meditation, qua minibus

\footnotetext{
${ }^{14}$ Frascari "The Tell-the-Tale Detail" p 30.
}

perficitur)."15 Thus, it is not only the final document that is important here but there is also value in the process of drawing itself. It is the act of drawing which develops a sense of knowledge of the site perhaps beyond that of researching the information alone. It calls upon the application of the information onto the site in a way that requires a construing during the drawing's construction.

\section{Conclusion}

This paper has questioned the objective nature of the map via the axonometric drawing. The map as an object is also a subjective representation. The axonometric as an objective drawing type becomes dependent upon the axonometer's subjectivity in its creation. The combination of this form of documentation and drawing type reveals the subjectivity of each.

The Vercoe and Harding map provides the plan forms for each potential building that existed on the site at the time the survey was conducted. Each building informs the next as each plan form evolves to suggest different building heights and building types.

${ }^{15}$ Frascari "Introduction" p 4. 
The axonometric relies on information other than the map it is based upon. The use of historic photography, published material and later maps inform part of the drawing. The rest of the drawing consists of an unraveling of the unknown by means of assumption. This assumption is subjective and an awareness of this subjectivity creates a close insight into the site in question. As the Vercoe and Harding map is a subjective portrayal of Auckland in 1866, similarly, the axonometric drawing from this map is a subjective portrayal of Auckland in 1866 from a current point of view. The axonometric is ultimately dependent upon the axonometer's own experience of the site and on their awareness of the cultural and social history that has evolved throughout the years beyond 1866 .

This process of documenting a site is not limited to the selected map and area selected for this project. The construing process of drawing the axonometric projection implements an intuitive response to the map and subsequently to the site. Through this process, the project proposes a way of investigating a site, a new reading of historical and current maps, which will create a layered and comprehensive understanding of a site; an understanding of place. 


\section{REFERENCES}

Bois, Yve-Alain "Metamorphosis of Axonometry" Daidalos (September 1981) 1:41-58.

Carlyon, Jenny and Morrow, Diana Urban Village: the story of Ponsonby, Freemans Bay and St. Mary's Bay Auckland: Random House, 2008.

Corner James "The Agency of Mapping: Speculation, Critique and Invention" Denis Cosgrove (ed) Mappings London: Reaktion Books, 1999:213-252.

Frascari, Marco "Introduction" Marco Frascari, Jonathan Hale and Bradley Starkey (eds) From Models to Drawings: Imagination and Representation in Architecture Abingdon: Routledge, 2007:i-xvii.

Frascari, Marco "The Tell-the-tale Detail" Via (1984) 7:22-37.

Marshall, Brian From Sextants to Satellites: A Cartographic Timeline for New Zealand Auckland: New Zealand Map Society, 2005.

Nevins, Deborah and Stern, Robert A M The Architect's Eye: American Architectural Drawings from 1799-1978 New York: Pantheon Books, 1979.

Reichlin, Bruno "Reflections: Interrelations between Concept, Representation and Built Architecture" Daidalos (September 1981) 1:60-73.

Salmond, Jeremy Old New Zealand Houses 1800-1940 Auckland: Reed Methuen, 1986

Schneider B "Perspective refers to the viewer, axonometry refers to the object" Daidalos (September 1981) 1:81-95.

Wood, Peter "Drawing the Line: A Working Epistemology for the Study of Architectural Drawing" Auckland: University of Auckland, PhD Thesis, 2002. 